\title{
A survey of activity-based costing in hotel industry
}

\author{
Zadollah Fathi $^{\mathrm{a}}$ and Elham Sadat Mousavi Dozdahiri ${ }^{\mathrm{b} *}$
}

${ }^{a}$ Faculty Member, Department of Industrial Management, Tehran Central Branch, Tehran, Iran

${ }^{b}$ Masters Student from Financial Management, Department of Industrial Management, Tehran Central Branch, Tehran, Iran

\begin{tabular}{l}
\hline C H R O N I C L E \\
\hline Article history: \\
Received March 25, 2015 \\
Received in revised format June \\
12015 \\
Accepted June 272015 \\
Available online \\
June 28 2015 \\
\hline Keywords: \\
Activity based cost \\
ABC \\
Hotel industry
\end{tabular}

\begin{abstract}
A B S T R A C T
This paper presents an empirical investigation on implementation of activity based cost (ABC) method in hotel industry. The study determines four possible factors of organizational, environmental, individual and technological, which could influence on ABC implementation. The study selects a sample of 205 employees who worked for Laleh International Hotel in Iran. Using one-way t-student test, the study has determined that all variables were effective on $\mathrm{ABC}$ implementation while individual factor was the most important one. In addition, correlation test has determined that all variables had meaningful correlations with each other. Further investigation indicates that gender did not play essential role for ABC implementation while experienced employee tended to be more effective for the success of ABC implementation.
\end{abstract}

\section{Introduction}

During the past few decades, there has been a growing competition in hotel industry and managers of most hotels attempt to use advanced techniques to lower their expenses. They also attempt to improve their management through strategic planning of their organizations (Collier \& Gregory, 1995). Haktanir and Harris (2005), for instance, explored performance measurement practices in the context of an independent hotel in Northern Cyprus. Haldma and Lääts (2002) investigated the management accounting practices of Estonian manufacturing companies, exploring the effects on them within a contingency theory framework. They provided some evidence that changes in cost and management accounting practices were related to shifts in the business and accounting environment as external contingencies, and with those in technology and organizational perspectives as internal contingencies. Activity based cost method (ABC) is one of management accounting methods where business processes are categorized into various activities and indirect costs are assigned into each activity according to some criteria (Agrawal et al., 1998; Cooper \& Kaplan, 1991, 1992). According to Tsai (1996), ABC is developed to improve the accuracy of product cost data extracted from the traditional cost system. ABC transforms indirect (overhead) expenses in the traditional cost system into direct expenses by

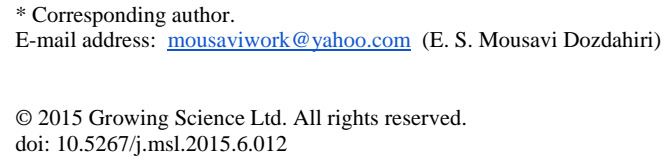


applying activities as the intermediums of cost assignment. ABC traces indirect expenses to the activities and then distributes the activity costs to the products. ABC has been extensively used in the practice and discussed in the literature. Tsai (1996) presented the ABC model for joint products. He used a simplified illustrative case to show the product costing for joint products under ABC.

Baykaso glu and Kaplano glu (2007) provided a service-costing framework for logistics firms, which were providing land transportation via trucks and concluded that their method could be very useful for the company in determining their true service costs. Innes et al. (2000) reviewed the results of two U.K. surveys of $A B C$ in the U.K.'s largest firms. These provide an opportunity to evaluate the changes occurred in the ABC adoption status of firms over a 5-year period. The study provided some comprehensive insights for the $\mathrm{ABC}$ users on the nature of the $\mathrm{ABC}$ systems in use and their designers.

Innes and Mitchell (1995) performed a survey on ABC in the U.K.'s largest 1000 firms. The survey was performed to ascertain the adoption rate of $A B C$ in these firms, the specific application of $A B C$, the users' perspectives on the success and relative importance of $A B C$ as well as the views of non-ABC users on $A B C$ and the possibilities. They reported that although ABC was implemented by a number of large firms its effect was often restricted in scope and it had also been rejected by a sizeable number. Therefore, there is a potential for considerable growth in its adoption among non-users.

Malmi (1999) explained what drives innovation diffusion in management accounting during its various phases. They defined four aspects with potential to describe the diffusion of accounting innovations are identified including the efficient-choice, forced selection, fad and fashion perspectives based on Abrahamson (1991). The diffusion of ABC in Finland provided an empirical context to investigate how these four perspectives could be implemented to management accounting innovation.

Cagwin and Bouwman (2002) studied the improvement in financial performance related to the use of $\mathrm{ABC}$, and the conditions under which such improvement could be achieved. Internal auditors furnish information regarding firm financial performance, extent of $\mathrm{ABC}$ usage, and enabling conditions that have been identified in the literature as affecting $\mathrm{ABC}$ efficacy.

Results show that there indeed is a positive association between ABC and improvement in ROI when $A B C$ is used concurrently with other strategic initiatives, when implemented in complex and diverse firms when used in environments where costs are relatively important, and when there are limited numbers of intra-company transactions. In addition, measures of success of ABC used in prior research appear to be predictors of improvement in financial performance.

\section{The proposed study}

This paper presents an empirical investigation to find out the feasibility of implementing activity based cost (ABC) method in hotel industry. The study determines four possible factors of organizational, environmental, individual and technological, which could influence on ABC implementation. The study selects a sample some employees who worked for Laleh International Hotel in Iran. The sample size is calculated as follows,

$$
n=\frac{N \times z_{\alpha / 2}^{2} \times p \times q}{\varepsilon^{2} \times(N-1)+z_{\alpha / 2}^{2} \times p \times q},
$$

where $N$ is the population size, $p=1-q$ represents the yes/no categories, $z_{\alpha / 2}$ is CDF of normal distribution and finally $\varepsilon$ is the error term. Since we have $p=0.5, z_{\alpha / 2}=1.96$ and $N=440$, the number of sample size is calculated as $n=205$. The study considers the following four hypotheses, 
1. Organizational factors, internal support, specialization, concentration, orientation and training, are significantly associated with the tendency of managers and employees to use ABC.

2. Factors associated with technology, the overhead, complexity and diversity of products and services, are significantly associated with the tendency of managers and employees to use ABC.

3. Environmental factors, competition, disorganized communication, strategy and system of government, are significantly associated with the tendency of managers and employees to use ABC.

4. Personal factors, allocation and responsibility, are significantly associated with managers and employees tend to use ABC.

The study has designed a questionnaire in Likert scale in four categories of organizational (14 questions), environmental (12 questions), individual (8 questions) and technological (18 questions). Kaiser-Meyer-Olkin (KMO) Measure of Sampling Adequacy is equal to 0.89. In addition, the implementation of Bartlett's Test of Sphericity yields Approx. Chi-Square of 254.04 with Sig. $=0.000$. These two validate the overall questionnaire. In addition, Cronbach alphas for four possible factors of organizational, environmental, individual and technological are 0.844, 0.848, 0.821 and 0.874, respectively and these factors are well above the minimum desirable level. Finally, KolmogorovSmirnov test has indicated that all components of the survey were normally distributed.

\section{The results}

In this section, we first present details of the implementation of one-way t-student test to verify the effects of the mentioned factors on ABC implementation. Table 1 presents the summary of our results.

\section{Table 1}

The summary of testing the effects of four variables on tendency of ABC implementation

\begin{tabular}{lcccccc}
\hline Attribute & \multirow{2}{*}{ t-value } & df & \multirow{2}{*}{ Sig. } & Mean & \multicolumn{2}{c}{$95 \%$ Interval } \\
Lower & Upper \\
\hline Organizational & 3.083 & 199 & 0.018 & 1.157 & 0.2695 & 2.0445 \\
Technological & 5.259 & 199 & 0 & 1.2876 & 0.7587 & 1.8166 \\
Environmental & 5.232 & 199 & 0 & 1.1757 & 1.6612 & 0.6903 \\
Individual & 4.516 & 199 & 0.001 & 1.1182 & 1.6531 & 0.5833 \\
\hline
\end{tabular}

As we can observe from the results of Table 1, all four factors have maintained meaning impact for ABC implementation. We have also examined the effects of gender on four mentioned factors and our results given in Table 2 have indicated that gender had no impact on ABC implementation.

Table 2

The summary of testing the difference between gender and ABC implementation.

\begin{tabular}{|c|c|c|c|c|c|c|c|c|c|}
\hline \multirow[b]{2}{*}{ Variable } & \multirow[b]{2}{*}{ Gender } & \multicolumn{2}{|c|}{ Statistics } & \multicolumn{2}{|c|}{ Leven test } & \multicolumn{3}{|c|}{ t-test } & \multirow[b]{2}{*}{ Result } \\
\hline & & Mean & Std. dev. & $\mathrm{F}$ & Sig. & $\mathrm{t}$-value & Sig. & Mean diff. & \\
\hline \multirow[t]{2}{*}{ Organizational } & Female & 3.218 & 0.554 & 6.678 & 0.011 & -1.728 & 0.087 & -0.135 & No difference \\
\hline & Male & 3.352 & 0.417 & & & & & & \\
\hline \multirow[t]{2}{*}{ Technological } & Female & 3.320 & 0.756 & 0.479 & 0.490 & 0.683 & 0.495 & 0.087 & No difference \\
\hline & Male & 3.233 & 0.682 & & & & & & \\
\hline \multirow[t]{2}{*}{ Environmental } & Female & 3.605 & 0.805 & 0.007 & 0.931 & -1.282 & 0.201 & -0.176 & No difference \\
\hline & Male & 3.781 & 0.751 & & & & & & \\
\hline \multirow[t]{2}{*}{ Individual } & Female & 4.168 & 0.566 & 1.095 & 0.297 & -0.388 & 0.699 & -0.037 & No difference \\
\hline & Male & 4.205 & 0.473 & & & & & & \\
\hline
\end{tabular}

Next, we have examined the effects of job experience on tendency towards ABC adaptation among employees using ANOVA test and according to the results of Table 3, this variable plays some important role only for the group with at least 15 years of job experiences. 


\section{Table 3}

The results of the ANOVA test between different groups of employees in terms of age and tendency to ABC adaptation

\begin{tabular}{|c|c|c|c|c|c|c|}
\hline \multirow{2}{*}{ Variable } & \multirow{2}{*}{ Job experience } & \multicolumn{2}{|r|}{ Statistics } & \multicolumn{2}{|c|}{ ANOVA } & \multirow{2}{*}{ Result } \\
\hline & & Mean & Standard deviation & F-value & Sig. & \\
\hline \multirow{4}{*}{ Individual } & Less than 5 & 3.009 & 0.459 & \multirow{4}{*}{6.819} & \multirow{4}{*}{0} & \multirow{4}{*}{ Difference } \\
\hline & $5-10$ & 3.221 & 0.556 & & & \\
\hline & $10-15$ & 3.211 & 0.502 & & & \\
\hline & $>15$ & 3.565 & 0.492 & & & \\
\hline \multirow{4}{*}{ Organizational } & Less than 5 & 3.271 & 0.729 & \multirow{4}{*}{0.156} & \multirow{4}{*}{0.926} & \multirow{4}{*}{$\begin{array}{c}\text { No } \\
\text { difference }\end{array}$} \\
\hline & $5-10$ & 3.307 & 0.777 & & & \\
\hline & $10-15$ & 3.345 & 0.718 & & & \\
\hline & $>15$ & 3.255 & 0.783 & & & \\
\hline \multirow{4}{*}{ Environmental } & Less than 5 & 3.8 & 0.745 & \multirow{4}{*}{0.662} & \multirow{4}{*}{0.576} & \multirow{4}{*}{$\begin{array}{c}\text { No } \\
\text { difference }\end{array}$} \\
\hline & $5-10$ & 3.67 & 0.691 & & & \\
\hline & $10-15$ & 3.616 & 0.821 & & & \\
\hline & $>15$ & 3.533 & 0.891 & & & \\
\hline \multirow{4}{*}{ Technological } & Less than 5 & 4.284 & 0.428 & \multirow{4}{*}{2.234} & \multirow{4}{*}{0.086} & \multirow{4}{*}{$\begin{array}{c}\text { No } \\
\text { difference }\end{array}$} \\
\hline & $5-10$ & 4.265 & 0.543 & & & \\
\hline & $10-15$ & 4.175 & 0.493 & & & \\
\hline & $>15$ & 3.982 & 0.715 & & & \\
\hline
\end{tabular}

Finally, in order to examine the effects of different factors on adaptation of ABC method, the proposed study uses Freedman test and Table 4 demonstrates the results of our survey.

\section{Table 4}

The summary of Freedman test

\begin{tabular}{lcc}
\hline Variable & Statistics & Rank \\
\hline Individual & 3.977 & 1 \\
Environmental & 2.862 & 2 \\
Technological & 2.138 & 3 \\
Organizational & 2.020 & 4 \\
\hline
\end{tabular}

As we can observe from the results of Table 4, individual factors are the most important item followed by environmental factors, technological and organizational factors. Finally, to show how effects each of these factors is, the study has implemented multi-regression analysis and Table 5 demonstrates the summary of the results.

\section{Table 5}

The summary of regression analysis

\begin{tabular}{lcccc}
\hline Variable & \multicolumn{2}{c}{ Unstandardized Coefficients } & Standardized Coefficients & Sig. \\
\cline { 2 - 5 } & $\beta$ & Std. Error & $\beta$ & .000 \\
\hline Intercept & .412 & .011 & .285 & .000 \\
Organizational & .248 & .005 & .273 & .000 \\
Technological & .244 & .005 & .302 & .000 \\
Environmental & .253 & .005 & .39 & .008 \\
Individual & .196 & .003 & & \\
\hline
\end{tabular}

Adjusted R-Square $=0.297$

As we can observe from the results of Table 5, all components have positive impacts on ABC implementation among employees of this hotel. Finally, we have used structural equation modeling (SEM) to examine the effects of different components on ABC implementation and Fig. 1 presents the summary of our results. As we can observe all statistics are within desirable levels and they confirm the results. 


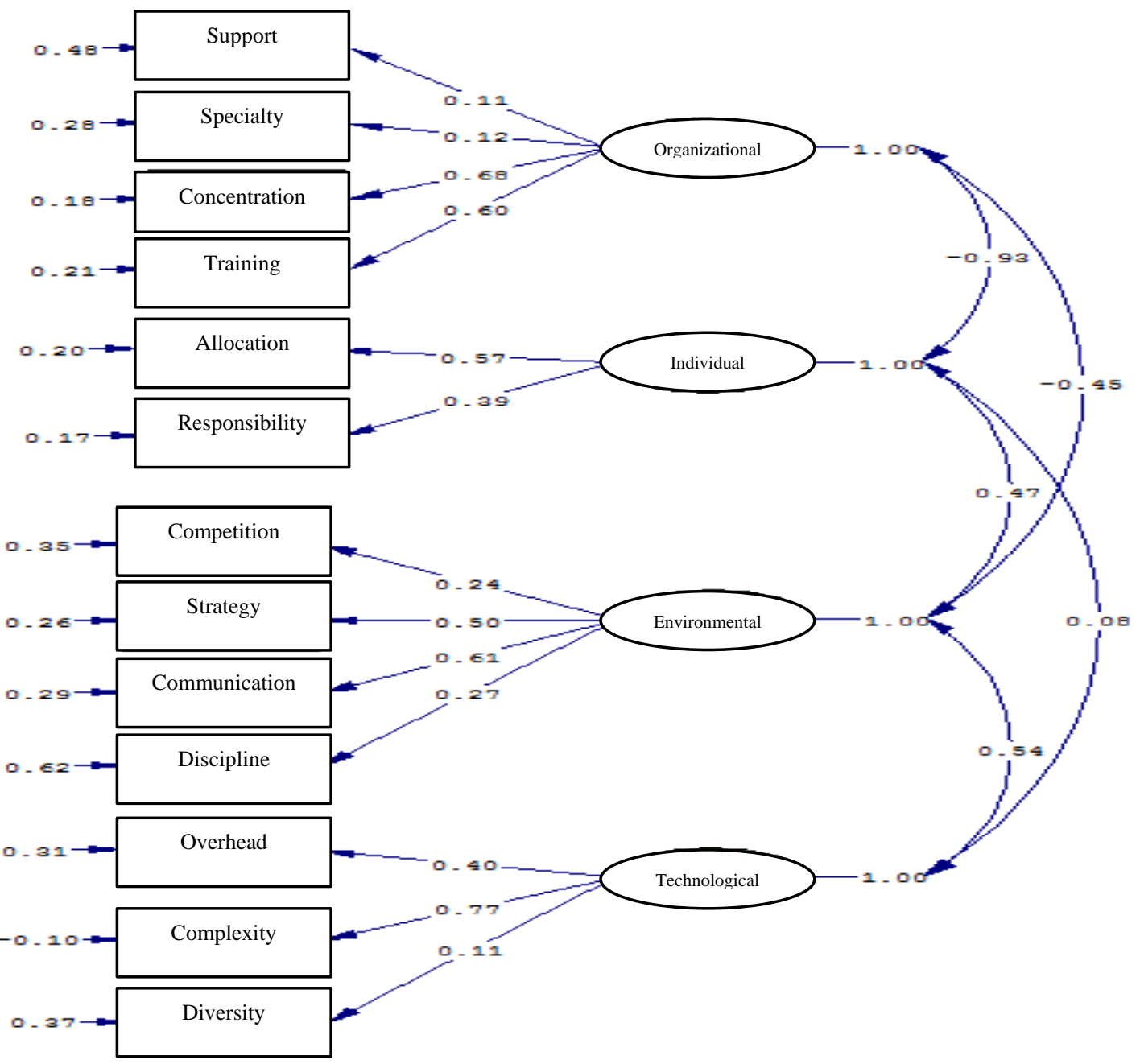

Chi-Square $=2.3, \mathrm{NFI}=0.97, \mathrm{NNFI}=0.95, \mathrm{CFI}=0.92, \mathrm{GFI}=0.94, \mathrm{AGFI}=0.97$

Fig. 1. The results of standard coefficients on SEM implementation

According to the results of Fig. 1, all components have maintained positive and meaningful impacts on $\mathrm{ABC}$ adaptation and training influences the most on $\mathrm{ABC}$ adaptation.

\section{Conclusion}

In this paper, we have presented an empirical investigation to learn more about the effects of different factors on ABC implementation on hotel industry. The survey has concluded that organizational, technological, individual and environmental factors influence on ABC implementation in hotel industry. In our survey, gender did not show any meaningful impact while employees with at least 15 years of job experience appeared to be more qualified for this project than other groups of people. Moreover, the implementation of Freedman test has indicated that individual factors were more important than other factors.

\section{Acknowledgement}

The authors would like to thank the anonymous referees for constructive comments on earlier version of this paper. 


\section{References}

Abrahamson, E. (1991). Managerial fads and fashions: the diffusion and rejection of innovations. Academy of Management Review, 16, 586-612.

Agrawal, S. P., Mehra, S., \& Siegel, P. H. (1998). Cost management system: an operational overview. Managerial Finance, 24(1), 60-78.

Baykaso glu, A., \& Kaplano glu, V. (2007). A service-costing framework for logistics companies and a case study. Management Research News, 30(9), 621-633.

Cagwin, D., \& Bouwman, M. J. (2002). The association between activity-based costing and improvement in financial performance. Management Accounting Research, 13(1), 1-39.

Collier, P., \& Gregory, A. (1995). Strategic management accounting: a UK hotel sector case study. International Journal of Contemporary Hospitality Management, 7(1), 16-21.

Cooper, R., \& Kaplan, R. S. (1991). Profit priorities from activity-based costing.Harvard Business Review, 69(3), 130-135.

Cooper, R., \& Kaplan, R. S. (1992). Activity-based systems: Measuring the costs of resource usage. Accounting Horizons, 6(3), 1-13.

Innes, J., \& Mitchell, F. (1995). A survey of activity-based costing in the UK's largest companies. Management Accounting Research, 6(2), 137-153.

Innes, J., Mitchell, F., \& Sinclair, D. (2000). Activity-based costing in the UK’s largest companies: a comparison of 1994 and 1999 survey results. Management Accounting Research, 11(3), 349-362.

Haktanir, M., \& Harris, P. (2005). Performance measurement practice in an independent hotel context: A case study approach. International Journal of Contemporary Hospitality Management, 17(1), 3950.

Haldma, T., \& Lääts, K. (2002). Contingencies influencing the management accounting practices of Estonian manufacturing companies. Management Accounting Research, 13(4), 379-400.

Malmi, T. (1999). Activity-based costing diffusion across organizations: an exploratory empirical analysis of Finnish firms. Accounting, Organizations and Society, 24(8), 649-672.

Tsai, W. H. (1996). Activity-based costing model for joint products. Computers \& Industrial Engineering, 31(3), 725-729. 